\title{
Extracorporeal shockwave therapy in musculoskeletal disorders
}

\author{
Ching-Jen Wang
}

\begin{abstract}
The sources of shockwave generation include electrohydraulic, electromagnetic and piezoelectric principles. Electrohydraulic shockwaves are high-energy acoustic waves generated under water explosion with high voltage electrode. Shockwave in urology (lithotripsy) is primarily used to disintegrate urolithiasis, whereas shockwave in orthopedics (orthotripsy) is not used to disintegrate tissues, rather to induce tissue repair and regeneration. The application of extracorporeal shockwave therapy (ESWT) in musculoskeletal disorders has been around for more than a decade and is primarily used in the treatment of sports related over-use tendinopathies such as proximal plantar fasciitis of the heel, lateral epicondylitis of the elbow, calcific or non-calcific tendonitis of the shoulder and patellar tendinopathy etc. The success rate ranged from 65\% to 91\%, and the complications were low and negligible. ESWT is also utilized in the treatment of non-union of long bone fracture, avascular necrosis of femoral head, chronic diabetic and non-diabetic ulcers and ischemic heart disease. The vast majority of the published papers showed positive and beneficial effects. FDA (USA) first approved ESWT for the treatment of proximal plantar fasciitis in 2000 and lateral epicondylitis in 2002. ESWT is a novel non-invasive therapeutic modality without surgery or surgical risks, and the clinical application of ESWT steadily increases over the years. This article reviews the current status of ESWT in musculoskeletal disorders.
\end{abstract}

Keywords: Extracorporeal shockwave therapy, Musculoskeletal disorders

Extracorporeal shockwave therapy (ESWT) began with an incidental observation of osteoblastic response pattern during animal studies in the mid-1980 that generated an interest in the application of ESWT to musculoskeletal disorders. In the past 10 to 15 years, shockwave therapy had emerged as the leading choice in the treatment of many orthopedic disorders including proximal plantar fasciitis of the heel [1-6], lateral epicondylitis of the elbow [7-10], calcific tendinitis of the shoulder [11,12] and. nonunion of long bone fracture [13-15]. More recently, the use of ESWT had expanded to the treatment of patellar tendinopathy (jumper's knee) and Achilles tendinopathy [16-19], and avascular necrosis of the femoral head [20-22]. ESWT has gained significant acceptance from Europe (Germany, Austria, Italy and others) to South America (Brazil, Columbia, Argentina and others), Asia (Korea, Malaysia, Taiwan and others) and North America

Correspondence: w281211@adm.cgmh.com.tw Department of Orthopedic Surgery, Section of Sports Medicine, Chang Gung University College of Medicine, Kaohsiung Chang Gung Memorial Hospital, 123 Ta-Pei Road. Niao Sung District, Kaohsiung City 833, Taiwan
(Canada and USA), and this had led to the change of European Society for Musculoskeletal Shockwave Therapy to International Society for Musculoskeletal Shockwave Therapy (ISMST) in 2000. In USA, FDA (Food and Drug Administration) first approved the specific shockwave device, OssaTron (High Medical Technology, Lengwil, Switzerland, now Sanuwave/Alpharetta, GA) for the treatment of proximal plantar fasciitis in 2000 and lateral epicondylitis of the elbow in 2003. FDA also approved Epos (Dornier Medical System, Kennesaw, GA) for the treatment of plantar fasciitis and Sonocur (Siemens Medical Systems, Iselin, NJ) for the treatment of lateral epicondylitis of the elbow in 2002, Orthospec (Medispec, Germantown, MD) and Orbasone (Orthometrix, White Plains, NY) for the treatment of plantar fasciitis in 2005. In the meantime, many off-label uses of ESWT were also studied including calcific tendinitis of the shoulder, patellar tendinopathy, Achilles tendinopathy, and non-union of long bone fracture, avascular necrosis of the femoral head and others. The vast majority of the published papers including randomized control trials and cohort studies showed

\section{() Biomed Central}


positive effects and evidence base medicine in favor of ESWT [1-6,8-12,23]. However, a few studies reported that ESWT is ineffective or less effective with the results comparable to the placebo effect $[7,24,25]$, and this has stirred up the debate and controversy. This article reviews the current status of ESWT in the treatment of musculoskeletal disorders.

\section{Principle of shockwave generation}

There are three main techniques through which shockwaves are generated. These are electrohydraulic, electromagnetic, and piezoelectric principles, and each of which represents a different technique of generating shockwaves. Electrohydraulic principle represents the first generation of orthopedic shockwave machine. Electrohydraulic shockwaves are high-energy acoustic waves generated by the underwater explosion with high-voltage electrode spark discharge, and the acoustic waves are then focused with an elliptical reflector and targeted at the diseased area to produce therapeutic effect [26]. It is characterized by large axial diameters of the focal volume and high total energy within that volume [27]. Shockwave generation through the electromagnetic technique involves the electric current passing through a coil to produce a strong magnetic field. A lens is used to focus the waves, with the focal therapeutic point being defined by the length of the focus lens. The amplitude of the focused waves increases by non-linearity when the acoustic wave propagates toward the focal point $[26,27]$ Shockwave of piezoelectric technique involves a large number (usually $>1,000$ ) of piezocrystals mounted in a sphere and receives a rapid electrical discharge that induces a pressure pulse in the surrounding water steepening to a shockwave. The arrangements of the crystals cause self-focusing of the waves toward the target center, and lead to an extremely precise focusing and high-energy within a defined focal volume. When comparing different shockwave devices, the important parameters include pressure distribution, energy density and the total energy at the second focal point in addition to the principle of shockwave generation of each device.

Shockwave pattern differs from ultrasound wave that is typically biphasic and has a peak pressure of 0.5 bar. Shockwave pattern is uni-phasic with the peak pressure as high as 500 bars [26]. In essence, the peak pressure of shockwave is approximately 1,000 times that of ultrasound wave. There are two basic effects of shockwave. The primary effect is the direct mechanical forces that result in the maximal beneficial pulse energy concentrated at the target point where treatment is provided; and the secondary effect is the indirect mechanical forces by cavitation which may cause negative effect or damage to the tissues [26-30].

\section{Mechanism of shockwave therapy}

The mechanism of shockwave therapy is not fully understood. The most important physical parameters of shockwave therapy for the treatment of orthopedic disorders include the pressure distribution, energy flux density and the total acoustic energy. In contrast to lithotripsy in which shockwaves disintegrate renal stones, orthopedic shockwaves are not being used to disintegrate tissue, but rather to microscopically cause interstitial and extracellular responses leading to tissue regeneration [26,27].

\section{Animal experiments}

\section{Shockwave therapy for bone healing}

Several studies had investigated the effects of shockwave therapy on fracture healing and articular cartilage in animal experiments. Haupt et al in an experimental model in rats, confirmed a positive effect of shockwave treatment on fracture healing [31]. Johannes et al showed the promotion of bony union with shockwave therapy in hypertrophic non-unions in dogs [32]. Wang et al demonstrated that shock wave therapy enhanced callus formation and induced cortical bone formation in acute fractures in dogs and the effect of shockwave therapy appeared to be timedependent [33]. Forriol et al, however, reached an alternative conclusion and thought that shockwave treatment might delay bone healing [34]. The conflicting results are due different types of animals and different shockwave dosages used. Wang et al had demonstrated that highenergy shockwave therapy produces a significantly higher bone mass including BMD (bone mineral density), callus size, ash and calcium contents, and better bone strength than the control group after fractures of the femurs in rabbits. The effects of low-energy shockwave therapy were less prevailing with comparable results as compared to the control. Therefore, the effect of shockwave therapy on bone mass and bone strength appeared to be dose- and time-dependent [35]. Many other studies also investigated the effect of shockwave therapy on bone healing in animals. The important findings included superoxide mediates shockwave induction of ERK-dependent osteogenic transcription factor (CBFA-1) and mesenchymal cells differentiation toward osteoprogenitors [36]. Extracorporeal shockwave promotes bone marrow stromal cell growth and differentiation toward osteo-progenitors associated with TGF- $\beta 1$ and VEGF induction [37]. Physical shockwave mediates membrane hyperpolarization and Ras activation for osteogenesis in human bone marrow stromal cells [38], Shockwave promotes bone regeneration by the recruitment of mesenchymal stem cells and expressions of TGF- $\beta 1$ and VEGF [39].

\section{Shockwave therapy for insertional tendinopathy}

Many studies investigated the effect of shockwave therapy on insertional tendinopathies. Rompe et al 
demonstrated dose-related effects of shockwave on rabbit tendo Achilles, and suggested that energy flux density of more than $0.28 \mathrm{~mJ} / \mathrm{mm}^{2}$ should not be used clinically in the treatment of tendon disorders [40]. In their study, a statistically significant increase of capillary formation was noted with higher energy shock wave $\left(0.60 \mathrm{~mJ} / \mathrm{mm}^{2}\right)$, which also caused more tissue reaction and potential damage to the tendon tissue. Wang et al had demonstrated that shockwaves enhance neovascularization with formation of new capillary and muscularized vessels at the tendon-bone junction of the Achilles tendons in dogs [41]. In another study in rabbit model, Wang et al further demonstrated that shockwave therapy induces the ingrowth of neo-vessels (neovascularization) including capillary and muscularized vessels than the control at the tendon-bone junction. Shockwave therapy releases angiogenetic growth and proliferating factors including eNOS, VEGF, and PCNA [42]. The $e$ NOS and VEGF began to rise in as early as one week and remained high for 8 weeks, then declined to baseline in 12 weeks; whereas the increase of PCNA and neo-vessels began in 1 weeks and persisted for 12 weeks and longer. Therefore, the mechanism of shockwave therapy may have involved the improvement in agniogenetic growth factors, which in turn induce neovascularization and improve blood supply at the tendon-bone junction of the Achilles tendon in rabbits.

Chronic tendinopathy is an overuse syndrome manifested with pain and tenderness due to mucoid and chondroid degeneration and formation of plump tenocytes and increased fibroblastic and myofibroblastic cells and absent inflammatory cells [43]. Some studies reported that chronic painful tendinopathy exhibited increased occurrence of sprouting nonvascular sensory, substance P-positive nerve fibers and decreased occurrence of vascular sympathetic nerve fibers, and suggested that the altered sensory-sympathetic innervation may play a role in the pathogenesis of tendinopathy [44]. It is believed that shockwave therapy alleviates pain due to insertional tendinopathy by the induction of neovascularization and improvement of blood supply to the tissue, and initiating repairs of the chronically inflamed tissues by tissue regeneration.

\section{Clinical applications Proximal plantar fasciitis}

Many studies investigated the effect of shockwave therapy in the treatment of proximal plantar fasciitis and reported a success rate ranging from $34 \%$ to $88 \%$ [1,45-62]. The majority of the published papers reported a positive and beneficial effect of ESWT in proximal plantar fasciitis. Rompe et al suggested that three weekly treatments with 1,000 impulses of low-energy shockwave at $0.06 \mathrm{~mJ} / \mathrm{mm}^{2}$ appear to be an effective therapy for plantar fasciitis with significant alleviation of pain and improvement in function [58]. Wang et al treated 79 patients ( 85 heels) with plantar fasciitis including 59 women and 20 men with an average age of 47 years (range 15-75 years) with shockwave therapy. At one-year follow-up, the overall results were $75.3 \%$ complaint free, $18.8 \%$ significantly better, $5.9 \%$ slightly better and none unchanged or worse. The recurrent rate was $5 \%$ [60]. It was concluded that shockwave therapy is a safe and effective modality in the treatment of proximal plantar fasciitis.

In contrast, few studies reported the opposite results of ESWT in the treatment of plantar fasciitis [7,24,25,63,64]. Buchbinder $\mathrm{R}$ et al compared 81 patients who received ultrasound-guided ESWT given weekly for 3 weeks to a total dose of at least $1,000 \mathrm{~mJ} / \mathrm{mm}^{2}$ with 85 patients in the placebo group who received treatment to a total dose of $6.0 \mathrm{~mJ} / \mathrm{mm}^{2}$, and concluded that no evidence to support a beneficial effect of ESWT over placebo on pain, function and quality of life [24]. Haake $M$ et al compared 135 patients allocated to ESWT with 137 patients allocated to placebo and the results showed that ESWT is ineffective in the treatment of chronic plantar fasciitis [64]. In a randomised double blind control trial, Speed CA et al concluded that no treatment effect of moderate dose of ESWT in subjects with plantar fasciitis. Efficacy may be highly dependent upon machine types and treatment protocol [25]. Therefore, controversy exists on the effect of ESWT in the treatment of chronic plantar fasciitis. The differences are probably due to the difference in methodology of the study, the patient selection criteria, the use of different devices, different energy levels and the total energy and the outcome measurements.

Several studies compared the effect of ESWT with surgery, local corticosteroid injection or physical therapy in the treatment of proximal plantar fasciitis $[62,65,66]$. Surgical treatment by plantar fasciotomy and ESWT showed comparable functional outcomes, however, ESWT incurred no surgical risks including surgical pain [62]. Physical therapy has shown to be comparable or better effect than ESWT in proximal plantar fasciitis, however, physical therapy is time consuming and inconvenient [63]. Corticosteroid injection shows better short-term effect, but the long-term results favor ESWT [66].

The application of ESWT in proximal plantar fasciitis is performed with either local anesthesia or no anesthesia. Several reports showed that ESWT is less effective when the treatment is performed with the use of local anesthesia $[67,68]$. The majority of our patients were treated with no local anesthesia. However, our observations failed to distinguish any difference between treatment with or without local anesthesia. In case patient is unable to tolerate the procedure because of pain during treatment, the anesthesia with constant sedation can be used. 
The complications of ESWT in proximal plantar fasciitis are low and negligible. Local reddening, ecchymosis, or mild hematoma, and migraine are among the list of complications. The complications can be successfully managed conservatively and spontaneous recovery is anticipated.

In summary, the literature review unveiled discrepancy and controversy on the effect of ESWT on proximal plantar fasciitis. Many factors can influence the effects of ESWT in the treatment of proximal plantar fasciitis. The vast majority of the published papers are in favor of ESWT. Additional studies are needed to validate the effectiveness of ESWT in the treatment of proximal plantar fasciitis.

\section{Lateral epicondylitis of the elbow}

Several studies investigated the effect of shockwave therapy in patients with lateral epicondylitis of the elbow, and the success rate ranged from $68 \%$ to $91 \%$ [69-75]. Rompe et al reported good or excellent outcome in $48 \%$ and an acceptable results in $42 \%$ at the final review at 24 weeks in 50 patients with chronic tennis elbow treated with 3,000 impulses of shockwave therapy compared with $6 \%$ and $24 \%$, respectively, in the control patients treated with 30 impulses [76]. Wang et al compared the results of shockwave therapy in 57 patients (58 elbows) with lateral epicondylitis of the elbow with a control group of 6 patients (6 elbows) with a follow-up of 12 to 26 months. The overall results of the treatment group were complaints free in 27 (61.4)\%, significantly better in 13 (29.5)\%, slightly better in $3(6.8 \%)$ and unchanged in $1(2.3 \%)$. Recurrent pain of lesser intensity was noted in 3 patients $(6.8 \%)$. In the control group, however, the results were unchanged in all 6 patients [77]. Few studies reported no effect of ESWT or less effect comparable to the placebo [78-83]. In a review of 9 placebo-controlled trials, Buchbinder et al concluded that there is "platinum" level that ESWT provides little or no benefit in term of pain and function in lateral elbow pain. There is "silver" level evidence that steroid injection may be more effective than ESWT $[7,78]$. Haake et al in a review of 20 studies concluded that no clinically relevant efficacy has been proven for the use of ESWT for lateral elbow pain $[79,80]$. Speed et al in a double blind randomized trial concluded that there appears to be a significant placebo effect of moderate dose of ESWT in subjects with lateral epicondylitis, but there is no evidence of added benefit of treatment when compared to sham therapy [82]. The differences were attributed to the patient selection, the techniques, the manufacture devices, the use of local anesthesia and the method of outcome measurements.

\section{Calcifying tendinitis of the shoulder}

The success rate of shockwave therapy in patients with calcific tendinitis of the shoulder was reported ranging from $78 \%$ to $91 \%$ [84-93]. Spindler et al reported complete pain relief and full shoulder joint movement in three patients two years after shockwave therapy, and a fragmentation of calcification was achieved after $24 \mathrm{~h}$ [12]. Wang et al compared the results of shockwave therapy in 37 patients (39 shoulders) with calcific tendonitis of the shoulder with a control group of 6 patients (6 shoulders). At 2- to 3-year follow-up, the overall results of the shockwave group were complaints free in $60.6 \%$, significantly better in $30.3 \%$, slightly better in $3.0 \%$ and unchanged in $6.1 \%$. Only two patients $(6 \%)$ showed recurrent pain of lesser intensity, and none showed worse symptoms. The results of the control group were slightly better in 1 (16.7\%) and unchanged in 5 (83.3\%). Radiographs showed complete elimination of calcium deposits in $57.6 \%$, partial elimination or fragmentation in $15.1 \%$, and unchanged in $27.3 \%$ for the shockwave group. For the control group, the calcium deposit was fragmented in $1(16.7 \%)$ and unchanged in 5 (83.3\%). None showed recurrence of calcium deposit 2 years after shockwave therapy. There was a correlation of functional improvement with the elimination of calcium deposit [94]. Jurgowski and Loew treated patients with two sessions of 2,000 impulses each of shockwave and reported a marked reduction of symptoms with an average of $30 \%$ improvement in the Constant score at the 12-week follow-up. Radiographs showed complete elimination of the calcification in seven patients, and partial elimination in five patients. Magnetic resonance imaging did not show any lasting damage to bone or soft tissue $[95,96]$. Rompe et al reported significant improvement in $72.5 \%$ of the patients and only six (15\%) of 40 patients treated with 1,500 impulses of shockwaves reported no improvement. Complete or partial disintegration of the calcium deposits was observed in $62.5 \%$ of the patients [74]. In another study, Rompe et al reported that shockwave therapy provides equal or better results than surgery in patients with calcifying tendonitis of the shoulder [97].

\section{Patellar tendinopathy (Jumper's knee) and Achilles tendinopathy}

Several studies have reported favorable results of shockwave therapy in athletes with Jumper's knee (patellar tendinopathy) with the success rate ranged from $73.5 \%$ to $87.5 \%[16,19,43,98-100]$. ESWT was also utilized in patients with patellar tendinopathy secondary to harvesting of the patellar tendon for ACL reconstruction. Wang et al compared 30 knees in 27 patients treated with ESWT with 24 knees in 23 patients treated conservatively, the results at 2- to 3-year follow-up showed $43 \%$ excellent, $47 \%$ good, $10 \%$ fair and none poor for the study group, and none excellent, $50 \%$ good, $25 \%$ fair and $25 \%$ poor for the control group $(P<0.05)$. Ultrasonographic examination showed a significant increase in the vascularity of the patellar tendon and a trend of reduction in the patellar tendon thickness after ESWT as compared to conservative treatments [43]. Peers KH et al 
compared 13 knees treated surgically with 15 knees received ESWT, and reported a comparable functional outcome in patient with patellar tendinopathy resistant to conservative treatments [100]. It appears that ESWT is effective in the management of patients with chronic patellar tendinopathy.

Many studies investigated the effect of ESWT in Achilles tendinopathy, and most reported favorable results with similar success rate as patellar tendinopathy [17,18,101-103]. Rompe et al compared 25 patients treated by eccentric stretching exercises with 25 patients treated with repetitive ESWT, and the results showed that eccentric loading is inferior to ESWT in the treatment of patients with chronic recalcitrant Achilles tendinopathy [101].

\section{ESWT in bone disorders}

Non-union and delayed union of long bone fracture Several studies investigated the effect of shockwave therapy for non-union and delayed union of long bone fractures, and reported the success rate of achieving bony union ranged from $50 \%$ to $85 \%$ [13,14,104-110]. Schaden et al reported a success of $85 \%$ in the treatment of 115 delayed and non-unions [106]. Valchanou et al [107] reported bony unions in 70 of 82 patients with delayed or chronic nonunion of fractures at various locations. Vogel et al reported a $60.4 \%$ union rate in 48 patients with pseudarthroses treated with 3,000 shockwave impulses [108]. Wang et al treated 72 patients with non-unions of long bone fracture with shockwave therapy, and reported a success rate of $82.4 \%$ bony union at 6-month follow-up [104]. Rompe et al reported a 50\% success rate in the treatment of delayed bone union with shockwaves in clinical study [109], whereas Schleberger and Senge [110] showed successful fracture healing in three of four pseudoarthroses treated with 2000 impulses of shockwaves. Recently, Elster EA et al reported an $80.2 \%$ success in 172 non-union of the tibia [14]. The results of ESWT in non-union of long bone appear to be comparable to surgical intervention. However, the advantages of ESWT include no surgery with no surgical pain and surgical risks.

AVNFH (Avascular necrosis of the femoral head) For symptomatic hips affected by AVNFH, conservative treatments are generally not successful, and surgery is indicated with the type of surgery varying according to the stage of the disease [111]. Core decompression with or without bone grafting is considered the gold standard of femoral head preserving procedures. However, the results of core decompression varied widely and most reports are unsatisfactory [112] ESWT was recently utilized in the treatment of early AVNFH. Several articles reported the positive effect of shockwave therapy for AVNFH [21,22,113-116]. Wang et al compared 23 patients with 29 hips treated with ESWT and 25 patients with 28 hips treated by core decompression with nonvascularized fibular bone grafting, total hip arthroplasty (THA) was performed in $3 \%$ and $21 \%(P=0.039)$ in 1 year, $10 \%$ and $32 \%(P=0.044)$ in 2 years and $24 \%$ and $64 \%(P=0.002)$ in 8 to 9 -year follow-up for the ESWT group and the surgical group respectively. Significant improvements in pain and function were noted at each time intervals favoring the ESWT. There was a trend of decrease in the size of the lesion in the ESWT group [22,117]. In animal experiment in rabbits, ESWT was shown to increase BMP-2 protein and mRNA, and upregulation of VEGF expression in necrotic subchondral bone of the femoral head. The up-regulation of VEGF may play a role inducing the ingrowth of neovascularization and improvement in blood supply to the femoral head $[118,119]$. These findings are in concert with our findings with histopathological examination and immunohistochemical analysis, ESWT was shown to promote angiogenesis and bone remodeling and regenerative effect in AVNFH [117]. It appears that ESWT is effective in the retardation or prevention of collapse of the femoral head in early AVNFH. The application of ESWT was also found effective in the treatment of corticosteriod induced AVNFH in patients with systemic lupus erythematosus [114]. Wang et al compared 15 patients with 26 hips in patients with systemic lupus erythematosus with the control of 24 patients with 29 hips, THA was performed in $12 \%$ and $14 \%$ respectively, and there were no difference in pain and function. It is concluded that the response of patients with SLE to ESWT for AVNFH is comparable to AVNFH in non-SLE patients [114].

Other disorders Several studies reported a positive effect of shockwave therapy in Peyronie's disease and complex regional pain syndrome (RSD or reflex sympathetic dystrophy) [120], osteoarthritis of the knee [121], spine fusion [122], malignant cells [123,124], and gene therapy [125]. Furthermore, the application of ESWT has been expanded to non-musculoskeletal diseases. Recent studies showed that ESWT is effective in chronic diabetic foot ulcers $[126,127]$ and ischemic heart disease $[128,129]$.

In conclusion, ESWT is a new non-invasive therapeutic modality with effectiveness, convenience and safety. ESWT has the potential of replacing surgery in many orthopedic disorders without the surgical risks. The complication rates are low and negligible. The exact mechanism of shockwave therapy remains unknown. In animal experiments, ESWT induces a cascade of biological responses and molecular changes including the ingrowth of neovascularization and up-regulation of angiogenetic growth factors leading to the improvement in blood supply and tissue regeneration. There is a great potential for translational research and development in the armamentarium of extracorporeal shockwave technology. 


\section{Authors' contributions}

C-JW participated in the study with the responsibility in protocol drafting, reference search, data collection and data analysis, manuscript writing and final proof of the manuscript.

\section{Competing interests}

The author declared that he did not receive any honoraria or consultancy fee in writing this manuscript. No benefit was received or will be received directly or indirectly from a commercial party related to the performance of this study. The author has served as the member of scientific advisory committee of Sanuwave (Alpharetta, GA).

\section{Received: 22 March 2011 Accepted: 20 March 2012}

Published: 20 March 2012

\section{References}

1. Buch M, Knorr U, Fleming L, Theodore G, Amendola A, Bachmann C, Zingas $C$, Siebert WE: Extracorporeal shockwave therapy in symptomatic heel spurs. An overview. Orthopade 2002, 31(7):637-44.

2. Perez M, Weiner R, Gilley JC: Extracorporeal shock wave therapy for plantar fasciitis. Clin Podi Med Surg 2003, 20(2):323-34.

3. Roehrig GJ, Baumhauer J, DiGiovanni BF, Flemister AS: The role of extracorporeal shock wave on plantar fasciitis. Foot Ankle Clin 2005, 10(4):699-712.

4. Strash WW, Perez RR: Extracorporeal shockwave therapy for chronic proximal plantar fasciitis. Clin Podi Med Surg 2002, 19(4):467-76.

5. Thomson CE, Crawford F, Murray GD: The effectiveness of extra corporeal shock wave therapy for plantar heel pain: a systematic review and meta-analysis. BMC Musculoskelet Disord 2005, 6:19.

6. Wilner JM, Strash WW: Extracorporeal shockwave therapy for plantar fasciitis and other musculoskeletal conditions utilizing the Ossatron-an update. Clin Podi Med Surg 2004, 21(3):441-7.

7. Buchbinder R, Green SE, Youd JM, Assendelft WJ, Barnsley L, Smidt N: Systematic review of the efficacy and safety of shock wave therapy for lateral elbow pain. J Rheum 2006, 33(7):1351-63.

8. Rompe JD, Theis C, Maffulli N: Shock wave treatment for tennis elbow. Orthopade 2005, 34(6):567-70

9. Rompe JD, Maffulli N: Repetitive shock wave therapy for lateral elbow tendinopathy (tennis elbow): a systematic and qualitative analysis. $\mathrm{Br}$ Med Bulletin 2007, 83:355-78.

10. Stasinopoulos D, Johnson Ml: Effectiveness of extracorporeal shock wave therapy for tennis elbow (lateral epicondylitis). Br J Sports Med 2005, 39(3):132-6.

11. Mouzopoulos G, Stamatakos M, Mouzopoulos D, Tzurbakis M: Extracorporeal shock wave treatment for shoulder calcific tendonitis: a systematic review. Skeletal Radiol 2007, 36(9):803-11.

12. Spindler A, Berman A, Lucero E, Braier M: Extracorporeal shock wave treatment for chronic calcific tendinitis of the shoulder. J Rheum 1998, 25(6):1161-3.

13. Cacchio A, Giordano L, Colafarina O, Rompe JD, Tavernese E, loppolo F, Flamini S, Spacca G, Santilli V: Extracorporeal shock-wave therapy compared with surgery for hypertrophic long-bone nonunions. J Bone Joint Surg -Am 2009, 91(11):2589-97, [Erratum appears in J Bone Joint Surg Am. 2010 May;92(5):1241].

14. Elster EA, Stojadinovic A, Forsberg J, Shawen S, Andersen RC, Schaden W: Extracorporeal shock wave therapy for nonunion of the tibia. J Orthop Trauma 2010, 24(3):133-41.

15. Xu ZH, Jiang Q, Chen DY, Xiong J, Shi DQ, Yuan T, Zhu XL: Extracorporeal shock wave treatment in nonunions of long bone fractures. Int Orthop 2009, 33(3):789-93

16. van Leeuwen MT, Zwerver J, van den Akker-Scheek I: Extracorporeal shockwave therapy for patellar tendinopathy: a review of the literature. Br J Sports Med 2009, 43(3):163-8.

17. Rasmussen S, Christensen M, Mathiesen I, Simonson O: Shockwave therapy for chronic Achilles tendinopathy: a double-blind, randomized clinical trial of efficacy. Acta Orthop 2008, 79(2):249-56.

18. Furia JP: High-energy extracorporeal shock wave therapy as a treatment for chronic noninsertional Achilles tendinopathy. Am J Sports Med 2008, 36(3):502-8.

19. Vulpiani MC, Vetrano M, Savoia V, Di Pangrazio E, Trischitta D, Ferretti A: Jumper's knee treatment with extracorporeal shock wave therapy: a long-term follow-up observational study. J Sports Med Physical Fitness 2007, 47(3):323-8.

20. Alves EM, Angrisani AT, Santiage MB: The use of extracorporeal shock waves in the treatment of osteonecrosis of the femoral head: a systematic review. Clin Rheuma 2009, 28(11):1247-51.

21. Kong FR, Liang YJ, Oin SG, Li JJ, Li XL: Clinical application of extracorporeal shock wave to repair and reconstruct osseous tissue framework in the treatment of avascular necrosis of the femoral head (ANFH). Zhongguo Gushang 2010, 23(1):12-5.

22. Wang CJ, Wang FS, Huang CC, Yang KD, Weng LH, Huang HY: Treatment for osteonecrosis of the femoral head: comparison of extracorporeal shock waves with core decompression and bone-grafting. J Bone Joint Surg - Am 2005, 87(11):2380-7.

23. Ogden JA, Alvarez RG, Levitt R, Marlow M: Shock wave therapy (lithotripsy) in musculoskeletal disorders. Clin Orthop 2001, 387:22-40.

24. Buchbinder R, Ptasznik R, Gordon J, Buchanan J, Prabaharan V, Forbes A Ultrasound-guided extracorporeal shock wave therapy for plantar fasciitis: a randomized controlled trial. JAMA 2002, 288(11):1364-72.

25. Speed CA, Nichols D, Wies J, Humphreys H, Richards C, Burnet S, Hazieman BL: Extracorporeal shock wave therapy for plantar fasciitis. A double blind randomized controlled trial. J Orthop Res 2003, 21(5):937-40.

26. Ogden JA, Tóth-Kischkat A, Schultheiss R: Principles of shock wave therapy. Clin Orthop 2001, 387:8-17.

27. In Extracorporeal shock waves in orthopaedics. Edited by: Siebert W, Buch M. Berlin, Springer Verlag; 1997:1-245.

28. Suhr D, Brummer F, Hulser DF: Cavitation-generated free radicals during shock wave exposure investigations with cell-free solutions and suspended cells. Ultrasound Med boil 1992, 17:761-8.

29. Tomita Y, Shima A: Mechanisms of impulsive pressure generation and damage pit formation by bubble collapse. J Fluid Mech 1986, 169:535-64

30. Zhong P, Cioanta I, Zhu S, Cocks FH, Preminger GM: Effects of tissue constraint in shock wave-induced bubble expansion in vivo. J Acoust Soc Am 1998, 104:3126-9.

31. Haupt G, Haupt A, Ekkernkamp A, Gerety B, Chvapil M: Influence of shockwave on fracture healing. J Urol 1992, 39:529-32.

32. Johannes EJ, Kaulesar Sukul DM, Matura E: High-energy shockwave for treatment of nonunion. An experiment on dogs. J Surg Res 1994, 57:246-52.

33. Wang $\mathrm{CJ}$, Huang HY, Chen HH, Pai CH, Yang KD: The effect of shock wave therapy on acute fractures of the tibia. A study in a dog model. Clin Orthop 2001, 387:112-8.

34. Forriol F, Solchaga L, Moreno JL, Candell J: The effect of shockwave on mature and healing cortical bone. Int Orhtop 1994, 8:325-9.

35. Wang CJ, Yang KD, Wang FS, Hsu CC, Chen HH: Shock wave treatment shows dose-dependent enhancement of bone mass and bone strength after fracture of the femur. Bone 2004, 34:225-230.

36. Wang FS, Wang CJ, Sheen-Chen SM, Kuo YR, Chen RF, Yang KD: Superoxide mediates shock wave induction of ERK-dependent osteogenic transcription factor (CBFA1) and mesenchymal cell differentiation toward osteoprogenitors. J Biolog Chemi 2002, 277(13):10931-7

37. Wang FS, Yang KD, Chen RF, Wang CJ, Sheen-Chen SM: Extracorporeal shock wave promotes growth and differentiation of bone-marrow stromal cells towards osteoprogenitors associated with induction of TGF-beta1. J Bone Joint Surg Br 2002, 84(3):457-61.

38. Wang FS, Wang $\mathrm{CJ}$, Huang $\mathrm{HC}$, Chung $\mathrm{H}$, Chen RF, Yang KD: Physical shock wave mediates membrane hyperpolarization and Ras activation for osteogenesis in human bone marrow stromal cells. Biochem Biophy Res Commun 2001, 287:648-55

39. Chen YJ, Wurtz T, Wang CJ, Kuo RY, Yang KD, Huang HC, Wang FS: Recruitment of mesenchymal stem cells and expression of TGF-beta 1 and VEGF in the early stage of shock wave-promoted bone regeneration of segmental defect in rats. J Orthop Res 2004, 22(3):526-34.

40. Rompe JD, Kirkpatrick CJ, Kullmer K, Schwitalle M, Krischek O: Dose-related effects of shock waves on rabbit tendo Achilis. J Bone Joint Surg Br 1998, 80B:546-52.

41. Wang $\mathrm{CJ}$, Huang $\mathrm{HY}$, Pai $\mathrm{CH}$ : Shock wave enhances neovascularization at the tendon-bone junction. J Foot Ankle Surg 2002, 41(1):16-22.

42. Wang CJ, Yang KD, Wang FS, Huang CC, Yang LJ: Shock wave induces neovascularization at the tendon-bone junction. A study in rabbits. $J$ Orthop Res 2003, 21:984-989. 
43. Wang CJ, Ko JY, Chan YS, Weng LH, Hsu SL: Extracorporeal shockwave for chronic patellar tendinopathy. Am J Sports Med 2007, 35(6):972-8.

44. Lian O, Dahl J, Ackermann PW, Frihagen F, Engebretsen L, Bahr R: Pronociceptive and antinociceptive neuromediators in patellar tendinopathy. Am J Sports Med 2006, 34(11):1801-8.

45. Chen HS, Chen LM, Huang TW: Treatment of painful heel syndrome with shock waves. Clin Orthop 2001, 387:41-6.

46. Chuckpaiwong B, Berkson EM, Theodore GH: Extracorporeal shock wave for chronic proximal plantar fasciitis: 225 patients with results and outcome predictors. J Foot Ankle Surg 2009, 48(2):148-55.

47. Gerdesmeyer L, Frey C, Vester J, Maier M, Weil L Jr, Weil L Sr, Russlies M, Stienstra J, Scurran B, Fedder K, Diehl P, Lohrer H, Henne M, Gollwitzer H: Radial extracorporeal shock wave therapy is safe and effective in the treatment of chronic recalcitrant plantar fasciitis: results of a confirmatory randomized placebo-controlled multicenter study. Am J Sports Med 2008, 36(11):2100-9.

48. Gollwitzer H, Diehl P, von Korff A, Rahlfs WW, Gerdesmeyer L: Extracorporeal shock wave therapy for chronic painful heel syndrome: a prospective, double blind, randomized trial assessing the efficacy of a new electromagnetic shock wave device. J Foot Ankle Surg 2007, 46(5):348-57.

49. Hammer DS, Adam F, Kreutz A, Kohn D, Seil R: Extracorporeal shock wave therapy (ESWT) in patients with chronic proximal plantar fasciitis: a 2year follow-up. Foot Ankle Int 2003, 24(11):823-8.

50. Hyer CF, Vancourt R, Block A: Evaluation of ultrasound-guided extracorporeal shock wave therapy (ESWT) in the treatment of chronic plantar fasciitis. J Foot Ankle Surg 2005, 44(2):137-43.

51. Ibrahim MI, Donatelli RA, Schmitz C, Hellman MA, Buxbaum F: Chronic plantar fasciitis treated with two sessions of radial extracorporeal shock wave therapy. Foot Ankle Int 2010, 31(5):391-7.

52. Kudo P, Dainty K, Clarfield M, Coughlin L, Lavoie P, Lebrun C: Randomized, placebo-controlled, double-blind clinical trial evaluating the treatment of plantar fasciitis with an extracoporeal shockwave therapy (ESWT) device: a North American confirmatory study. J Orthop Res 2006, 24(2):115-23.

53. Metzner G, Dohnalek C, Aigner E: High-energy Extracorporeal Shock-Wave Therapy (ESWT) for the treatment of chronic plantar fasciitis. Foot Ankle Int 2010, 31(9):790-6.

54. Norris DM, Eickmeier KM, Werber BR: Effectiveness of extracorporeal shockwave treatment in 353 patients with chronic plantar fasciitis. J Am Podi Med Asso 2005, 95(6):517-24

55. Ogden JA, Alvarez RG, Levitt RL, Johnson JE, Marlow ME: Electrohydraulic high-energy shock-wave treatment for chronic plantar fasciitis. J Bone Joint Surg - Am 2004, 86(10):2216-28.

56. Rajkumar P, Schmitgen GF: Shock waves do more than just crush stones: extracorporeal shock wave therapy in plantar fasciitis. Int J Clin Pract 2002, 56(10):735-7.

57. Rompe JD, Decking J, Schoellner C, Nafe B: Shock wave application for chronic plantar fasciitis in running athletes. A prospective, randomized, placebo-controlled trial. Am J Sports Med 2003, 31(2):268-75.

58. Rompe JD, Schoellner C, Nafe B: Evaluation of low-energy extracorporeal shock-wave application for treatment of chronic plantar fasciitis. J Bone Joint Surg- Am 2002, 84(3):335-41.

59. Wang CJ, Chen HS, Chen WS, Chen LM: Treatment of painful heels using extracorporeal shock wave. J Formosan Med Asso 2000, 99(7):580-3.

60. Wang CJ, Chen HS, Huang TW: Shockwave therapy for patients with plantar fasciitis: a one-year follow-up study. Foot Ankle Int 2002, 23(3):204-7

61. Wang CJ, Wang FS, Yang KD, Weng LH, Ko JY: Long-term results of extracorporeal shockwave treatment for plantar fasciitis. Am J Sports Med 2006, 34(4):592-6.

62. Weil LS Jr, Roukis TS, Weil LS, Borrelli AH: Extracorporeal shock wave therapy for the treatment of chronic plantar fasciitis: indications, protocol, intermediate results, and a comparison of results to fasciotomy. J Foot Ankle Surg 2002, 41(3):166-72.

63. Greve JM, Grecco MV, Santos-Silva PR: Comparison of radial shockwaves and conventional physiotherapy for treating plantar fasciitis. Clinics (SaO Paulo, Brazil) 2009, 64(2):97-103.

64. Haake M, Buch M, Schoellner C, Goebel F, Vogel M, Mueller I, Hausdorf J, Zamzow K, Schade-Brittinger C, Mueller HH: Extracorporeal shock wave therapy for plantar fasciitis: randomised controlled multicentre trial. BMJ 2003, 327(7406):75.
65. Othman AM, Ragab EM: Endoscopic plantar fasciotomy versus extracorporeal shock wave therapy for treatment of chronic plantar fasciitis. Arch Orthop Trauma Surg 2010, 130(11):1343-7.

66. Yucel I, Ozturan KE, Demiraran Y, Degirmenci E, Kaynak G: Comparison of high-dose extracorporeal shockwave therapy and intralesional corticosteroid injection in the treatment of plantar fasciitis. J Am Podi Med Asso 2010, 100(2):105-10.

67. Labek G, Auersperg V, Ziernhold M, Poulios N, Bohler N: Influence of local anesthesia and energy level on the clinical outcome of extracorporeal shock wave-treatment of chronic plantar fasciitis. Zeitschrift fur Orthopadie und Ihre Grenzgebiete 2005, 143(2):240-6.

68. Rompe JD, Meurer A, Nafe B, Hofmann A, Gerdesmeyer L: Repetitive lowenergy shock wave application without local anesthesia is more efficient than repetitive low-energy shock wave application with local anesthesia in the treatment of chronic plantar fasciitis. J Ortho Res 2005, 23(4):931-41.

69. Furia JP: Safety and efficacy of extracorporeal shock wave therapy for chronic lateral epicondylitis. Am J Orthop (Chatham, NJ) 2005, 34(1):13-9, discussion 19, 2005 Jan.

70. Ko JY, Chen HS, Chen LM: Treatment of lateral epicondylitis of the elbow with shock waves. Clin Orthop 2001, 387:60-7.

71. Ozturan KE, Yucel I, Cakici H, Guven M, Sungur I: Autologous blood and corticosteroid injection and extracoporeal shock wave therapy in the treatment of lateral epicondylitis. Orthopedics 2010, 33(2):84-91.

72. Radwan YA, ElSobhi G, Badawy WS, Reda A, Khalid S: Resistant tennis elbow: shock-wave therapy versus percutaneous tenotomy. Int Orthop 2008, 32(5):671-7.

73. Rompe JD, Decking J, Schoellner C, Theis C: Repetitive low-energy shock wave treatment for chronic lateral epicondylitis in tennis players. Am J Sports Med 2004, 32(3):734-43.

74. Rompe JD, Eysel P, Hopf C, Krischek O, Vogel J, Burger R, Jage J, Heine J: [Extracorporeal shockwave therapy in orthopedics. Positive results in tennis elbow and tendinosis calcarea of the shoulder]. Fortschritte der Medizin 1997, 26(18):29-33.

75. Spacca G, Necozione S, Cacchio A: Radial shock wave therapy for lateral epicondylitis: a prospective randomised controlled single-blind study. Europa Medicophysica 2005, 41(1):17-25.

76. Rompe JD, Hope C, Kullmer K, Heine J, Burger R: Analgesic effect of extracorporeal shock-wave therapy on chronic tennis elbow. J Bone Joint Surg Br 1996, 78(2):233-7.

77. Wang CJ, Chen HS: Shock wave therapy for patients with lateral epicondylitis of the elbow: a one- to two-year follow-up study. Am J Sports Med 2002, 30(3):422-5.

78. Buchbinder R, Green SE, Youd JM, Assendelft WJ, Barnsley L, Smidt N: Shock wave therapy for lateral elbow pain. Cochrane Database of Systematic 2005, , 4: CD003524, [Update of Cochrane Database Syst Rev. 2002, (1):CD003524; PMID: 11869669] Reviews.

79. Haake M, Hunerkopf M, Gerdesmeyer L, Konig IR: Extracorporeal shockwave therapy (ESWT) in epicondylitis humeri radialis. A review of the literature. Orthopade 2002, 31(7):623-32.

80. Haake M, Konig IR, Decker T, Riedel C, Buch M, Muller HH: Extracorporeal shock wave therapy in the treatment of lateral epicondylitis: a randomized multicenter trial. Extracorporeal Shock Wave Therapy Clinical Trial Group. J Bone Joint Surg - Am 2002, 84(11):1982-91.

81. Melikyan EY, Shahin E, Miles J, Bainbridge LC: Extracorporeal shock-wave treatment for tennis elbow. A randomised double-blind study. J Bone Joint Surg Br 2003, 85(6):852-5.

82. Speed CA, Nichols D, Richards C, Humphreys H, Wies JT, Burnet S, Hazleman BL: Extracorporeal shock wave therapy for lateral epicondylitisa double blind randomised controlled trial. J Orthop Res 2002, 22(5):895-898.

83. Staples MP, Forbes A, Ptasznik R, Gordon J, Buchbinder R: A randomized controlled trial of extracorporeal shock wave therapy for lateral epicondylitis (tennis elbow). J Rheuma 2008, 35(10):2038-46.

84. Cacchio A, Paoloni M, Barile A, Don R, de Paulis F, Calvisi V, Ranavolo A, Frascarelli M, Santilli V, Spacca G: Effectiveness of radial shock-wave therapy for calcific tendinitis of the shoulder:single-blind, randomized clinical study. Phys Ther 2006, 86(5):672-82.

85. Daecke W, Kusnierczak D, Loew M: Long-term effects of extracorporeal shockwave therapy in chronic calcific tendinitis of the shoulder. J Shoulder Elbow Surg 2002, 11(5):476-80. 
86. Hsu CJ, Wang DY, Tseng KF, Fong YC, Hsu HC, Jim YF: Extracorporeal shock wave therapy for calcifying tendinitis of the shoulder. J Shoulder Elbow Surg 2008, 17(1):55-9.

87. Jakobeit C, Winiarski B, Jakobeit S, Welp L, Spelsberg G: Ultrasound-guided, high-energy extracorporeal shock-wave treatment of symptomatic calcareous tendinopathy of the shoulder. ANZ J Surg 2002, 72(7):496-500.

88. Krasny C, Enenkel M, Aigner N, Wlk M, Landsiedl F: Ultrasound-guided needling combined with shock-wave therapy for the treatment of calcifying tendonitis of the shoulder. J Bone Joint Surg Br 2005, 87(4):501-7.

89. Pan PJ, Chou CL, Chiou HJ, Ma HL, Lee HC, Chan RC: Extracorporeal shock wave therapy for chronic calcific tendinitis of the shoulders: a functional and sonographic study. Arch Phy Med Rehab 2003, 84(7):988-93.

90. Peters J, Luboldt W, Schwarz W, Jacobi V, Herzog C, Vogl TJ: Extracorporeal shock wave therapy in calcific tendinitis of the shoulder. Skeletal Radiol 2004, 33(12):712-8.

91. Pleiner J, Crevenna R, Langenberger H, Keilani M, Nuhr M, Kainberger F, Wolzt M, Wiesinger G, Quittan M: Extracorporeal shockwave treatment is effective in calcific tendonitis of the shoulder. A randomized controlled trial. Wien Klin Wochenschr 2004, 116(15-16):536-41.

92. Rompe JD, Burger R, Hopf C, Eysel P: Shoulder function after extracorporal shock wave therapy for calcific tendinitis. J Shoulder Elbow Surg 1998, 7(5):505-9.

93. Wang CJ, Ko JY, Chen HS: Treatment of calcifying tendinitis of the shoulder with shock wave therapy. Clin Orthop 2001, 387:83-9.

94. Wang CJ, Yang KD, Wang FS, Chen HH, Wang JW: Shock wave therapy for calcific tendinitis of the shoulder: a prospective clinical study with twoyear follow-up. Am J Sports Med 2003, 31(3):425-30.

95. Jurgowski W, Loew M, Cotta H, Staehler G: Extracorporeal shock wave treatment of calcareous tendonitis of the shoulder. J Endourol 1993, 7(Suppl 1):13-17.

96. Loew M, Daecke W, Kusnierezak D, Rahmanzadeh M, Ewerbeck V: Shock wave application in calcifying tendinitis of the shoulder: prediction of outcome by imaging. Arch Orthop Trauma Surg 2000, 120:43-8.

97. Rompe JD, Zoellner J, Nafe B: Shock wave therapy versus conventional surgery in the treatment of calcifying tendinitis of the shoulder. Clin Orthop 2001, 387:72-82.

98. Zwerver J, Dekker F, Pepping GJ: Patient guided Piezo-electric Extracorporeal Shockwave Therapy as treatment for chronic severe patellar tendinopathy: a pilot study. J Back Musculoskeletal Rehab 2010, 23(3):111-5

99. Hsu RW, Hsu WH, Tai CL, Lee KF: Effect of shock-wave therapy on patellar tendinopathy in a rabbit model. J Orthop Res 2004, 22(1):221-7.

100. Peers KH, Lysens RJ, Brys P, Bellemans J: Cross-sectional outcome analysis of athletes with chronic patellar tendinopathy treated surgically and by extracorporeal shock wave therapy. Clin J Sport Med 2003, 13(2):79-83.

101. Rompe JD, Furia J, Maffulli N: Eccentric loading compared with shock wave treatment for chronic insertional achilles tendinopathy. A randomized, controlled trial. J Bone Joint Surg - Am 2008, 90(1):52-61.

102. Furia JP: High-energy extracorporeal shock wave therapy as a treatment for insertional Achilles tendinopathy. Am J Sports Med 2006, 34(5):733-40.

103. Furia JP: Extracorporeal shockwave therapy in the treatment of chronic insertional Achilles tendinopathy. Orthopade 2005, 34(6):571-8.

104. Wang CJ, Chen HS, Chen CE, Yang KD: Treatment of nonunions of long bone fractures with shock waves. Clin Orthop Rel Res 2001, 387:95-101.

105. Haupt G: Use of extracorporeal shock wave in the treatment of pseudoarthrosis, tendinopathy and other orthopaedic disease. J Urology 1997, 158:4-11.

106. Schaden W, Fischer A, Sailer A: Extracorporeal shock wave therapy of nonunion or delayed osseous union. Clin Orthop 2001, 387:90-4

107. Valchanou VD, Michailow P: High-energy shock waves in the treatment of delayed and nonunion of fractures. Int Orthop 1991, 151:181-4.

108. Vogel J, Hopf C, Eysel P, Rompe JD: Application of extracorporeal shockwaves in the treatment of pseudarthrosis of the lower extremity: preliminary results. Arch Orthop Trauma Surg 1997, 116:480-3.

109. Rompe JD, Rosendahl T, Schöllner C, Theis C: High-energy extracorporeal shock wave treatment of nonunions. Clin Orthop 2001, 387:102-111.

110. Schleberger $R$, Senge $T$ : Noninvasive treatment of long bone pseudoarthrosis by shock waves (ESWL). Acta Orthop Trauma Surg 1992, 111:224-7
111. Mont MA, Jones LC, Hungerford DS: Nontraumatic osteonecrosis of the femoral head: ten years later. J Bone Joint Surg - Am 2006, 88(5):1117-32.

112. Mont MA, Carbone JJ, Fairbank AC: Core decompression versus nonoperative management for osteonecrosis of the hip. Clin Orthop 1996, 324:169-78.

113. Ludwig J, Lauber S, Lauber HJ, Dreisilker U, Raedel R, Hotzinger H: Highenergy shock wave treatment of femoral head necrosis in adults. Clin Orthop 2001, 387:119-26.

114. Lin PC, Wang CJ, Yang KD, Wang FS, Ko JY, Huang CC: Extracorporeal shockwave treatment of osteonecrosis of the femoral head in systemic lupus erythematosis. J Arthroplasty 2006, 21(6):911-5.

115. Wang CJ, Ko JY, Chan YS, Lee MS, Chen JM, Wang FS, Yang KD, Huang CC: Extracorporeal shockwave for hip necrosis in systemic lupus erythematosus. Lupus 2009, 18(12):1082-6.

116. Wang CJ, Wang FS, Yang KD, Huang CC, Lee MS, Chan YS, Wang JW, Ko JY: Treatment of osteonecrosis of the hip: comparison of extracorporeal shockwave with shockwave and alendronate. Arch Orthop Trauma Surg 2008, 128(9):901-8.

117. Wang CJ, Wang FS, Ko JY, Huang HY, Chen CJ, Sun YC, Yang YJ: Extracorporeal shockwave therapy shows regeneration in hip necrosis. Rheumatology 2008, 47(4):542-6.

118. Ma HZ, Zeng BF, Li XL, Chai YM: Temporal and spatial expression of BMP2 in sub-chondral bone of necrotic femoral heads in rabbits by use of extracorporeal shock waves. Acta Orthopaedica 2008, 79(1):98-105.

119. Ma HZ, Zeng BF, Li XL: Upregulation of VEGF in subchondral bone of necrotic femoral heads in rabbits with use of extracorporeal shock waves. Calcif Tissue Int 2007, 81(2):124-31.

120. Notarnicola A, Moretti L, Tafuri S, Panella A, Filipponi M, Casalino A, Panella M, Moretti B: Shockwave therapy in the management of complex regional pain syndrome in medial femoral condyle of the knee. Ultrasound Med Biology 2010, 36(6):874-9.

121. Wang CJ, Ko JY, Weng LH, Wang JW, Chen JM, Sun YC, Yang YJ: Extracorporeal Shockwave Shows Regression of Osteoarthritis of the Knee in Rats. J Surg Res 2011.

122. Lee TC, Yang YL, Chang NK, Lin TS, Lin WC, Liu YS, Wang CJ: Biomechanical testing of spinal fusion segments enhanced by extracorporeal shock wave treatment in rabbits. Chang Gung Med J 2009, 32(3):276-82.

123. Brümmer F, Suhr D, Hulser DF: Sensitivity of normal and malignant cells to shock waves. J Stone Dis 1992, 4(3):243-8.

124. Russo P, Stephenson RA, Mies C, Huryk R, Heston WD, Melamed MR, Fair WR: High energy shock waves suppress tumor growth in vitro and in vivo. J Uro 1986, 135(3):626-8.

125. Lauer U, Burgelt E, Squire Z, Messmer K, Hofschneider PH, Gregor M, Delius M: Shock wave permeabilization as a new gene transfer method. Gene Therapy 1997, 4(7):710-5.

126. Wang CJ, Kuo YR, Wu RW, Liu RT, Hsu CS, Wang FS, Yang KD: Extracorporeal shockwave for diabetic foot ulcers. J Surg Res 2009, 152:96-103.

127. Kuo YR, Wang CT, Wang FS, Chiang YC, Wang CJ: Extracorporeal shockwave therapy enhanced wound healing via increasing topical blood perfusion and tissue regeneration in a rat model of STZ-induced diabetes. Wound Repair Reg 2009, 17(4):522-30.

128. Kikuchi Y, Ito K, Ito Y, Shiroto T, Tsuburaya R, Aizawa K, Hao K, Fukumoto Y, Takahashi J, Takeda M, Nakayam M, Yasuda S, Kuriyama S, Tsuji I, Shimokawa H: Double-blind and placebo-controlled study of the effectiveness and safety of extracorporeal cardiac shockwave therapy for severe angina pectoris. Circ J 2010, 74(3):589-91.

129. Sheu JJ, Sun CK, Chang LT, Fang HY, Chung SY, Chua S, Fu M, Lee FY, Kao YH, Ko SF, Wang CJ, Yen CH, Leu S, Yip HK: Shock wave-pretreated bone marrow cells further improve left ventricular function after myocardial infarction in rabbits. Ann Vasc Surg 2010, 24(6):809-821.

doi:10.1186/1749-799X-7-11

Cite this article as: Wang: Extracorporeal shockwave therapy in musculoskeletal disorders. Journal of Orthopaedic Surgery and Research 2012 7:11. 